\title{
Children's Attitudes Toward People With AIDS in Puerto Rico: Exploring Stigma Through Drawings and Stories
}

\author{
Milagritos González-Rivera \\ University of Puerto Rico, Mayagüez \\ José A. Bauermeister \\ University of Michigan, Ann Arbor
}

\begin{abstract}
AIDS stigma refers to prejudice and discrimination directed at people or groups perceived to have HIV/AIDS (Herek, 1999). Although AIDS stigma has been found in adolescent and adult populations, few researchers have explored it among children. Misconceptions about people with AIDS (PWA) might lead to negative attitudes toward PWA and obstruct HIV prevention efforts. The authors assessed 110 Puerto Rican children's attitudes toward PWA using drawings $(n=65)$ and stories $(n=45)$. Although participants held stigmatizing attitudes toward PWA across both methods, the approaches captured different beliefs and attitudes. Drawings depicted PWA as physically deteriorated and performing socially condemned behaviors, whereas stories describing PWA highlighted children's fear of contagion and death. Stigma toward PWA was more pronounced than toward other illnesses (e.g., cancer). The study highlights the importance of assessing children's attitudes through creative data collection procedures.
\end{abstract}

Keywords: HIV/AIDS; stigma; attitudes; children; Latino; drawing; stories

A IDS stigma refers to "prejudice, discounting, discrediting, and discrimination directed at people perceived to have AIDS or HIV, and the individuals, groups, and communities with which they are associated" (Herek, 1999, p. 1107). In a national survey measuring the prevalence of AIDS stigma in the United States, Herek, Capitanio, and Widaman (2002, 2005) found that overt expressions of AIDS stigma (e.g., persons with AIDS [PWA] should be segregated) declined over the past decade, whereas the proportion of people holding misconceptions of HIV transmission (e.g., AIDS can be acquired by being sneezed or coughed on) and covert expressions of AIDS stigma (e.g., parents' discomfort with sending a child to attend a school where there is a child who has AIDS) increased. AIDS stigma has also been identified as prevalent in other countries (Hamra, Ross, Karuri, Orrs, \& D'Agostino, 2005; Parker \& Aggleton, 2003). Negative attitudes toward people with AIDS decrease the efficacy of health communication prevention messages and reduce the possibility of an open conversation about HIV/AIDS in our society (Wang, 1998). In this article, we assess children's AIDS stigma through the creation of stories and drawings.
Researchers have categorized AIDS stigma into two domains, instrumental and symbolic, and have highlighted the importance of separating both for intervention purposes (Herek et al., 2005; Pryor, Reeder, Yeadon, \& Hesson-MacInnis, 2004). Instrumental stigma reflects fear of AIDS as an illness and the desire to protect oneself from getting infected. A disease is likely to evoke stigma if its cause is perceived to be the bearer's responsibility, if it evokes social disapproval, if its course is unalterable or degenerative, if it is contagious, and if it disrupts social interaction or is perceived by others as repellent or upsetting (Goffman, 1963; Herek et al., 2005). Given that AIDS manifests all of these characteristics, some expression of stigma is probably inevitable (Herek, 1999). Moreover, some community sectors have historically used AIDS stigma to express negative attitudes toward

\footnotetext{
Authors' Note: We thank Drs. Gregory Herek and Caroline Wang for their invaluable insight and feedback during the development of this manuscript. Special thanks to Ada Pimentel, Maria DeLeón, Lucrecia Aguirre, and Yolanda Vazquez, who assisted in the data collection for this project. We also thank the children, parents, and schools for their participation in the study.
} 
groups disproportionately affected by the epidemic, particularly men who have sex with men (MSM) and injection drug users (IDU) (Herek, 1999; Herek et al., 2005).

Symbolic stigma stems from the perceived associations between AIDS and socially disliked outgroups identified with the disease (Herdt, 2001; Reidpath \& Chan, 2005). Specific forms of symbolic stigma vary according to each community's experiences of the AIDS epidemic (Ramirez-Valles, Fergus, Reisen, Poppen, \& Zea, 2005; Varas-Diaz, Serrano-Garcia, \& Toro-Alfonso, 2005). In a nationally representative sample, Capitanio and Herek (1999) found that African Americans' attitudes toward IDU predicted their attributions toward PWA better than their attitudes toward gay men did. For Whites, however, their attitudes toward gay men predicted their attribution toward PWA better than their attitudes toward IDU did. These racial variations in AIDS stigma reflect the higher incidence of HIV transmission through injection drug use among the African American community and through MSM contact among the White community, respectively. Misconceptions about HIV/AIDS knowledge and attitudes might hinder the efficacy of HIV education messages received across the life course by creating biased perceptions of who is susceptible to HIV/AIDS (Schiff et al., 2003). Consequently, information about AIDS transmission and equivocal attributions regarding who gets HIV/AIDS might limit HIV prevention efforts.

Most HIV education interventions target the knowledge, attitudes, and behaviors of adolescents and young adults (Schiff et al., 2003). The average age of onset for sexual initiation, however, continues to decrease in the United States (Allan Guttmacher Institute, 2005), suggesting the need to deliver HIV prevention education at younger ages. Nonetheless, HIV education interventions focusing on preadolescent youth have been the source of heated debate due to reluctance to talk about sexual behaviors with this population (Herek et al., 2005).

AIDS prevention efforts targeting young children tend to emphasize factual information about HIV/AIDS (Schiff et al., 2003; Siegel, 1993). Although information alone might be insufficient to promote the adoption of preventive behaviors, its relevance for dispelling misconceptions about, fear of, and stigma toward people with AIDS should not be underestimated. Children might be as likely as adults to develop negative attitudes toward HIV prevention messages and people with AIDS (Herek \& Capitanio, 1999). Henker,
Whalen, and O'Neil (1995) found that 10-year-old children without formal education about HIV/AIDS reported worrying about HIV/AIDS and fearing people with AIDS. Furthermore, researchers exploring children's AIDS-related knowledge, attitudes, and behaviors have suggested that AIDS stigma is prevalent among children (Hamra et al., 2005; Tinsley, Lees, \& Sumartojo, 2004).

Cole, Roberts, and McNeil (1996) examined fourth-, fifth-, and sixth-grade children's perceptions of peers described as having one of four types of disease (i.e., AIDS, diabetes, asthma, or cystic fibrosis). Children rated peers with AIDS as more responsible for their disease than any other sick-role behavior. In another study, Hoppe, Wells, Wilsdon, Gillmore, and Morrison (1994) conducted focus groups with children in grammar school to elicit information about their knowledge and attitudes about AIDS. Although they observed high levels of accurate HIV transmission knowledge across the entire sample, children in all grade levels displayed misconceptions about people with AIDS and had difficulty applying their knowledge to a hypothetical situation of encountering a child with AIDS in school.

AIDS stigma in children can be directed at individuals who are several steps removed from the disease (Pryor, Reeder, \& Landau, 1999). In their study of 2nd, 5th, 8th, and 11th graders, the researchers showed one group of students a photograph of an age-matched, same-gender peer who was described as having AIDS. Another group of students was also shown photographs of age-matched, same-gender peers but were told that the older brother of the person in the photograph used illegal drugs, was homosexual, had a serious illness, was a victim of serious misfortune, or had recently died. Based on the results of their questionnaires, the researchers found that youth held similar negative attitudes toward a person with AIDS and to a peer symbolically associated with AIDS through an older brother. The situations proposed in Pryor et al.'s (1999) research, however, might have biased the children's responses by focusing only on socially marginalized groups and undesirable outcomes. We addressed this limitation by allowing children to explore their feelings and opinions toward people with AIDS through the use of drawing and storytelling. This approach might facilitate the elicitation of beliefs, attitudes, and misconceptions not measured or identified through a questionnaire, avoid the problem of children's shyness about discussing a sensitive topic in focus groups or individual interviews, and provide 
insights into the mental image that children have of various individuals and groups (Aldridge et al., 2004; Cox, 2005; Yuen, 2004). Unfortunately, most studies using this approach have focused on White samples (Burkitt, Barrett, \& Davis, 2004). Given that variations in children's attitudes by ethnicity have been found (Tinsley et al., 2004), and because little is known about how Latino children perceive people who are sick, we explored how Puerto Rican preadolescent children perceive PWA.

Puerto Rico has an estimated HIV incidence rate of 324.3 cases per 100,000 inhabitants (Centers for Disease Control and Prevention [CDC], 2005). Although researchers have found evidence that people with HIV/AIDS in Puerto Rico experience stigma in their communities (Gonzalez, 1997; VarasDiaz et al., 2005), little is known about AIDS stigma among Puerto Rican children. A seminal study by Ramirez and Vargas (1996) explored second graders' attitudes toward people with AIDS in Puerto Rico through the use of stories. Ramirez and Vargas's thematic analysis of children's narratives suggested Puerto Rican children associated AIDS with drug use; held highly stereotypical images of people with AIDS, such as attributing malevolent intent; and described PWA as having deteriorated bodies. However, this seminal study had three limitations. First, the researcher identified themes found only in the short stories of 20 students. Visual representations of illness might help identify themes not easily expressed by word-based methods (Guillemin, 2004; Kendrick \& McKay, 2002). Therefore, a more extensive exploration of how Puerto Rican children represent PWA is warranted. Second, Ramirez and Vargas did not assess whether children's representation of PWA were different from their representation of other illnesses. Finally, the researchers assessed only second graders' attitudes towards PWA. Children beginning the transition into adolescence might have different beliefs about and attitudes toward PWA than second graders do.

So that we can address the current gaps in this literature, our study has two objectives. First, we explore preadolescent students' attitudes toward and beliefs about PWA using drawings and stories in a sample of Puerto Rican fifth-grade children. Second, we compare children's representations of PWA to their representations of people with different sickrole behaviors (i.e., people who are healthy, people who have a cold, and people with cancer). We discuss the advantages and disadvantages of using these data collection methods and their implications for assessing Puerto Rican children's instrumental and symbolic stigma toward PWA.

\section{Method}

\section{Participants}

We recruited 110 fifth-grade students (mean age of 10 years; $52 \%$ female) of diverse socioeconomic backgrounds enrolled in private schools in the West Region of Puerto Rico. The West Region covers 15 municipalities with more than half a million inhabitants (U.S. Census, 2006). We collected data from 10 of the 35 private schools in the region. Eight of the schools were religious (five Catholic, one Adventist, one Presbyterian, and one Evangelical), and two schools were secular.

\section{Procedures}

After acquiring institutional review board (IRB) approval, we contacted the directors of the 10 schools and requested their help in completing the project. After the schools' directors endorsed the study, we contacted the parents of fifth graders in each school through a letter explaining the purpose of the study and specifying the research procedures. A teacher in each school was assigned to collect the signed consent forms. Five students did not participate because they forgot to return their parents' signed consent forms. There were no complaints or concerns from parents regarding the study.

In each classroom, we first explained the activities to be carried out and asked whether any students wished to decline to participate in the study. None of the students declined their right to participate (see Irwin \& Johnson, 2005, for additional discussion on the implications of interviewing children). We then proceeded to assign each student in a classroom randomly to a drawing group or a story group. Students participated in only one type of activity to reduce fatigue and to avoid the possibility that participating in one condition could spill over into the performance of the other. We conducted all data collection sessions in Spanish. All sessions lasted approximately 90 minutes. After all groups completed their task, the entire fifth grade came together to discuss AIDS prevention in a question-and-answer session. 


\section{Drawing Groups}

Children's drawings have often been used to diagnose emotional disorders, learning disabilities, cognitive impairment, and family interactions (Fury, Carlson, \& Sroufe, 1997). Although analysis of drawings has been historically common in studies of children with developmental or psychological disorders, such drawings have also been useful in gaining access to information and attitudes that cannot be tapped into verbally (Bendelow \& Pridmore, 1998; Diem-Wille, 2001).

The students in the drawing groups $(n=65)$ were given pencils and $11 \times 14$ " $(28 \times 35.5 \mathrm{~cm})$ sheets of paper, and were allowed to sit on the floor, separate from each other. They were then asked to draw five pictures: (a) a healthy person, (b) a person with cancer, (c) a person with AIDS, (d) a person with a cold, and (e) a person with AIDS and the child. Once each student had completed the drawings, he or she was individually interviewed. Each child was asked his or her name; whether he or she knew someone with cancer, AIDS, or a cold; what the person in each picture was doing; and what the student knew about AIDS. We then elicited each student's consent to display the drawings anonymously outside the classroom. All students gave permission to share their drawings. The researchers also asked follow-up questions to clarify the content of each drawing. The researchers recorded the answers to these questions and attached an identification code to the drawings and notes. These notes were used to cross-validate our interpretation of students' drawings and to ensure that children's perspectives were honored throughout the analyses.

\section{Story-Writing Groups}

Stories written by children have been used to identify their concerns and attitudes (Sumida, 2000), and to identify the attributions that children make about different groups of people (Ramirez \& Vargas, 1996). The students in the story-writing groups $(n=45)$ sat in a circle. The session began with an informal conversation about what constitutes a story and a sharing of stories that the children remembered. Following the pedagogical approach used by fifth-grade teachers to discuss a story, the researchers reviewed the four basic elements of a story (characters, setting, plot, and resolution) and led the students in folding a piece of paper into four sections and writing each element of the story in one of the sections of the paper. This approach also ensured that we had comparable elements across all stories. The group then practiced writing a story about a pet together. Next, they received pencils and sheets of paper and were asked to write short stories individually about (a) a person with AIDS, (b) a person with cancer, and (c) a person with AIDS and themselves. As students finished writing their stories, we asked for students' consent to exhibit their stories anonymously outside the classroom. All students gave their permission. After completing their stories, some children volunteered to read their stories to the group.

\section{Data Analysis}

\section{Drawings}

All participants completed the drawing of the person with a cold, the healthy person, the person with AIDS, and the person with AIDS and him- or herself (65 drawings of each type). Five students did not know anything about cancer, and thus, only 60 drawings of a person with cancer were obtained. We content analyzed these 320 drawings to identify the children's representations of illness and, specifically, people with AIDS.

We used the initial descriptive information provided during the child's interview to develop a coding scheme. For each drawing, the senior author identified the gender and age group of the persons illustrated using the drawings and notes recorded during the individual interviews. She then compared the body size and height of people depicted in all the drawings by each participant and identified any physical marks, clothing style, actions depicted, and facial features. Comparisons, for example, identified if each child drew the PWA with the same head and body proportions as the healthy person, the person with cancer, or the person with a cold. If a child drew characters with a full body, we compared how their clothing and accessories were illustrated.

A research assistant coded each of the drawings by tallying the physical attributes and behaviors present in each drawing. The senior researcher then compared this coding scheme with the description given for each drawing in students' interviews. The mean interrater reliability for all drawings was .94 based on percent of agreement between the two reviewers. Coding disagreements between the researcher and the research assistant were discussed and resolved by a third coder. We found no discernable pattern in the disagreements. 
Figure 1

Drawing of a Healthy Person ("Saludable"), a Person With a Cold ("Catarro"), a Person With Cancer ("Cancer"), and a Person With AIDS ("SIDA," Misspelled as "Cida")
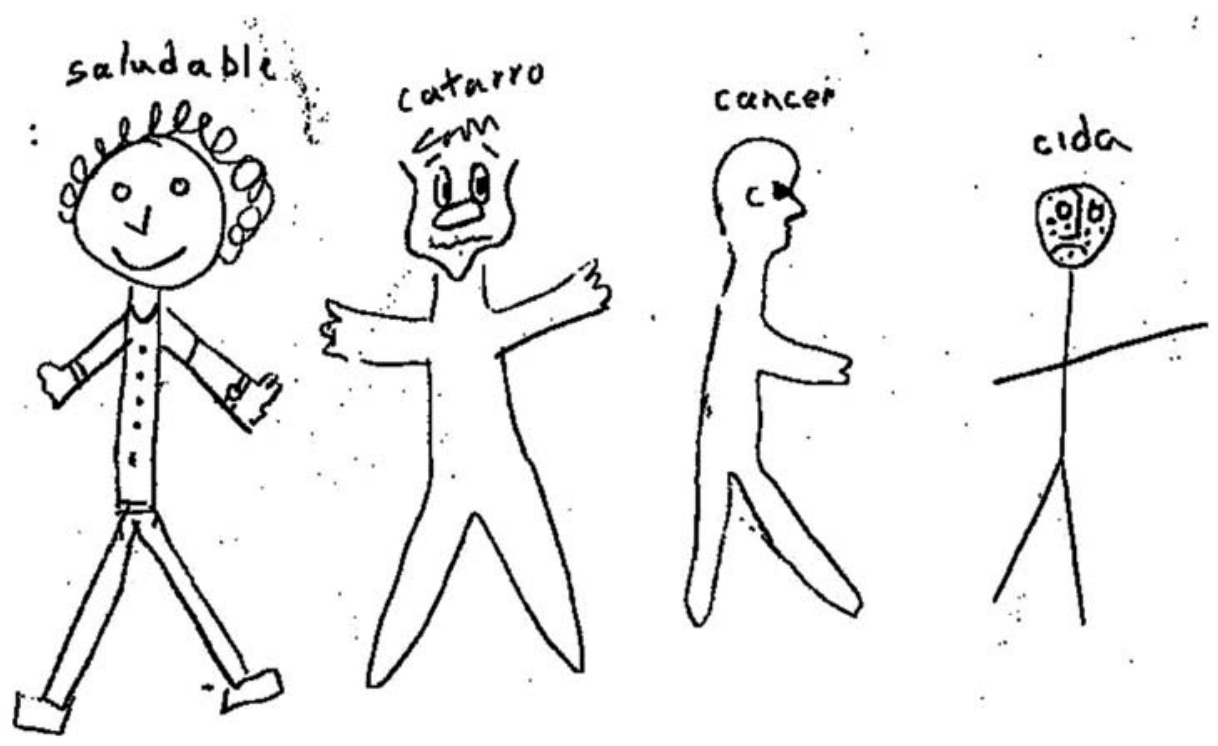

\section{Stories}

As with the drawing activity, we gathered descriptive information to develop a coding scheme for the stories. All 135 stories were content analyzed to identify the qualities and actions attributed in each story. The researchers read all the stories, identified their main topics, and created a thematic coding sheet. Then, we reread every story to identify how many stories included each of the themes identified. The mean interrater reliability was .93 based on percent of agreement between the two reviewers. Disagreements were resolved by a third coder. We found no pattern across coding disagreements.

\section{Findings}

\section{Drawings}

\section{Comparisons Across Drawings}

Overall, fifth-grade students represented people who were healthy or without a cold more positively than people with cancer or people with AIDS in their drawings. People who were healthy or had a cold usually had smiling faces. In Figure 1, for example, we juxtapose a fifth grader's drawing of a person who is healthy ("saludable"), who has a cold ("catarro"), who has cancer ("cancer"), and who has AIDS ("SIDA," misspelled as "cida") to contrast the types of drawings and highlight the main themes found in the analyses of students' drawings. In this drawing, the healthy man is fully dressed and is smiling, whereas all characters with a sick-role behavior do not have any clothing accessories. The man with a cold is represented as sneezing by the drawn dots ranging from his enlarged nose to the floor. The student's representation of a man with cancer had a large bald head and an angry expression in his face. However, the representation of a person with AIDS was drawn using a stick-figure rather than full-body pictures. Furthermore, the PWA has an enlarged, saddened face covered in sores. We discuss general patterns for each sick-role scenario in greater detail below.

\section{Representations of a Healthy Person and a Person With a Cold}

We found no major differences in how fifth graders represented people who were healthy and people who had a cold. Usually, children illustrated these characters by drawing full-bodied, clothed, standing figures. The children usually distinguished the healthy person and the person with a cold by indicating that the 
person with a cold was sneezing or drawing people with a cold as having a bigger nose (see Figure 1). However, the body size (i.e., weight and height), hairstyle, and other facial features (i.e., smile and eyes) of the person with a cold were similar in most drawings. These drawings also focused mostly on clothing elements, such as including shirt patterns, belts, wrist watches, and shoes in their portrayals rather than focusing on their facial and body characteristics. Students did not attribute any behavior to characters who were healthy or who had a cold.

\section{Representations of People With Cancer}

Most students represented children or adult women in their drawings of people with cancer. More than half of students' drawings of people with cancer depicted thin-bodied characters. However, few drawings highlighted additional physical characteristics. Two drawings, for example, illustrated a person with cancer as being bald. Another fifth grader's drawing depicted a woman after having a mastectomy by drawing only one breast on her body.

Unlike the drawings of people described as healthy or as having a cold, fifth-grade students attributed behaviors to people with cancer. Fifth graders depicted the person with cancer as holding a cigarette and being covered by smoke in more than a quarter of the drawings. In a few drawings, the person with cancer was smoking while drinking. Figure 2, for example, illustrates an adult woman who is smoking while holding a beverage in her hand. Students did not depict any other behaviors in the drawings of people with cancer.

\section{Representation of Person With AIDS}

Children represented all PWA as "skinny." Most drawings represented male adults. Most fifth graders focused on detailing PWA's faces in their drawings rather than on their bodies. Most children's representations of PWA included notable physical features, such as being bald, having sores or bruises, and having decaying teeth. Some drawings portrayed PWA without any identifiable physical features. Instead, student depicted their clothing features, such as chains, tattoos, and/or earrings. In three drawings, students represented PWA as wearing everyday clothes and without any identifiable physical features.

Most of the drawings depicted PWA as carrying out one or more behaviors. Similar to people with cancer,
Figure 2

\section{Woman With Cancer While She Smokes and Drinks a Beverage}

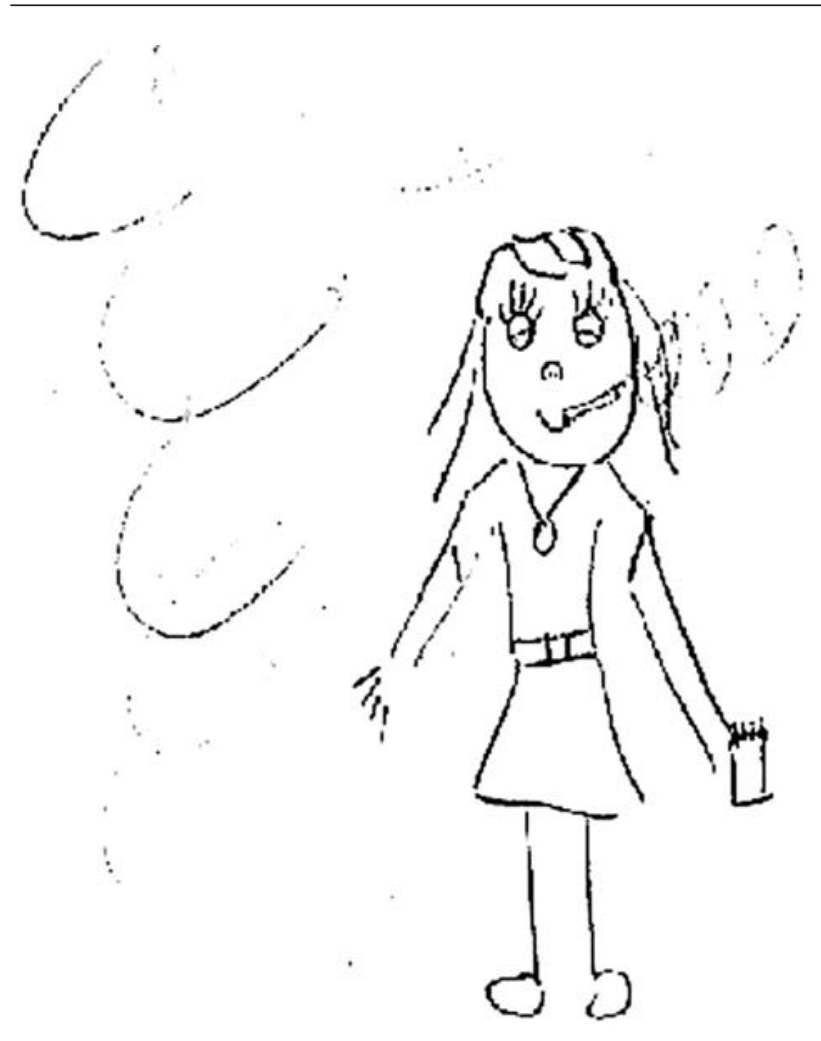

some PWA were smoking in a few drawings. In most drawings, children represented PWA while they engage in transmission-related risk behaviors, such as using a needle. In Figure 3, for example, a fifth-grade student represented a PWA as having sores and decaying teeth, wearing earrings in both ears, smoking, and having a syringe in his arm. None of the children drew PWA engaging in any sex risk behaviors.

In a few drawings, children represented PWA as dangerous. In these drawings, PWA carried weapons (e.g., a knife or gun). In Figure 4, for example, one fifth grader illustrated a male PWA as having sores throughout his body, wearing an earring, and carrying a knife in his left pocket and a gun in his right pocket.

Some drawings included PWA in victim-role behaviors such as begging for money or lying in a hospital bed. In Figure 5, for example, a fifth-grade student depicts a PWA who is smoking and injecting a syringe in his arm as he begs for money in the road. 
Figure 3

Drawing of a Person With AIDS

Wearing Earrings Who Is Smoking and Injecting a Needle Into His or Her Arm

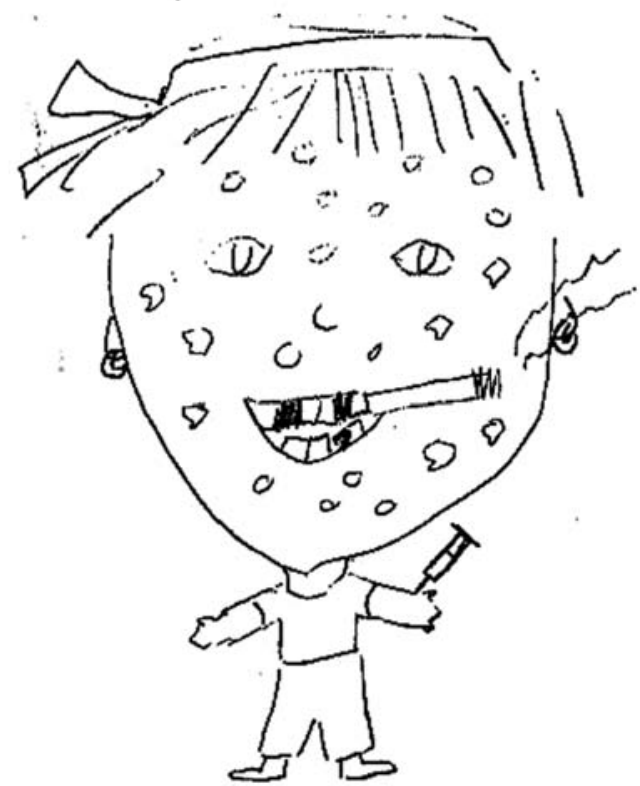

Representation of the Person With AIDS With the Participant

When students were asked to draw themselves with a PWA, most fifth graders illustrated threatening scenarios, such as the PWA attacking the child with a needle or weapon, offering drugs to the child, or using drugs in front of the child. Figure 6, for example, illustrates a fifth grader crying, scared as he witnesses two PWA, a man and a woman, both with sores on their faces, injecting drugs through a syringe. Few drawings depicted the child and the person with AIDS in caring or helpful interactions, such as holding hands or asking for money.

\section{Stories}

Most of the stories included children as main characters and included topics related to drugs or death (see Table 1). Thematic topics for each type of story are presented below alongside examples of the children's stories.

\section{Stories About People With Cancer}

The topics most frequently found in the stories about people with cancer included undergoing surgery
Figure 4

Drawing of a Male Individual Who Has AIDS-

The Person Has Skin Sores, Wears an Earring, and Carries a Knife and a Gun

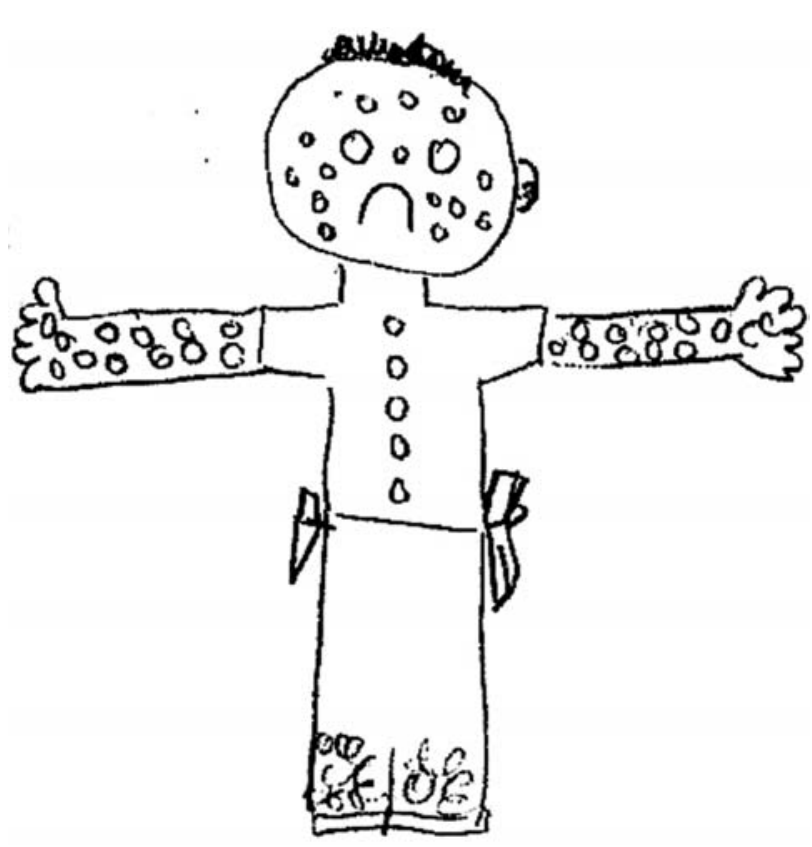

Figure 5

Drawing of a Person With AIDS Using a Needle While Asking for Money in a Street

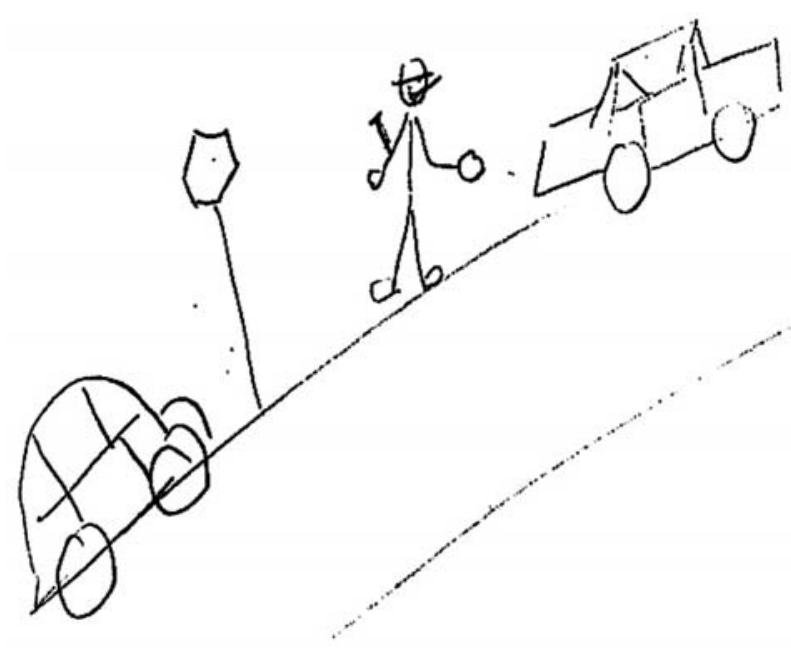

(21 stories), smoking (15 stories), and healing (14 stories). Although with less frequency, some stories mentioned other themes, such as death (6 stories), 
Figure 6

Drawing of a Child Witnessing Two People Living With AIDS Using an Injection Drug
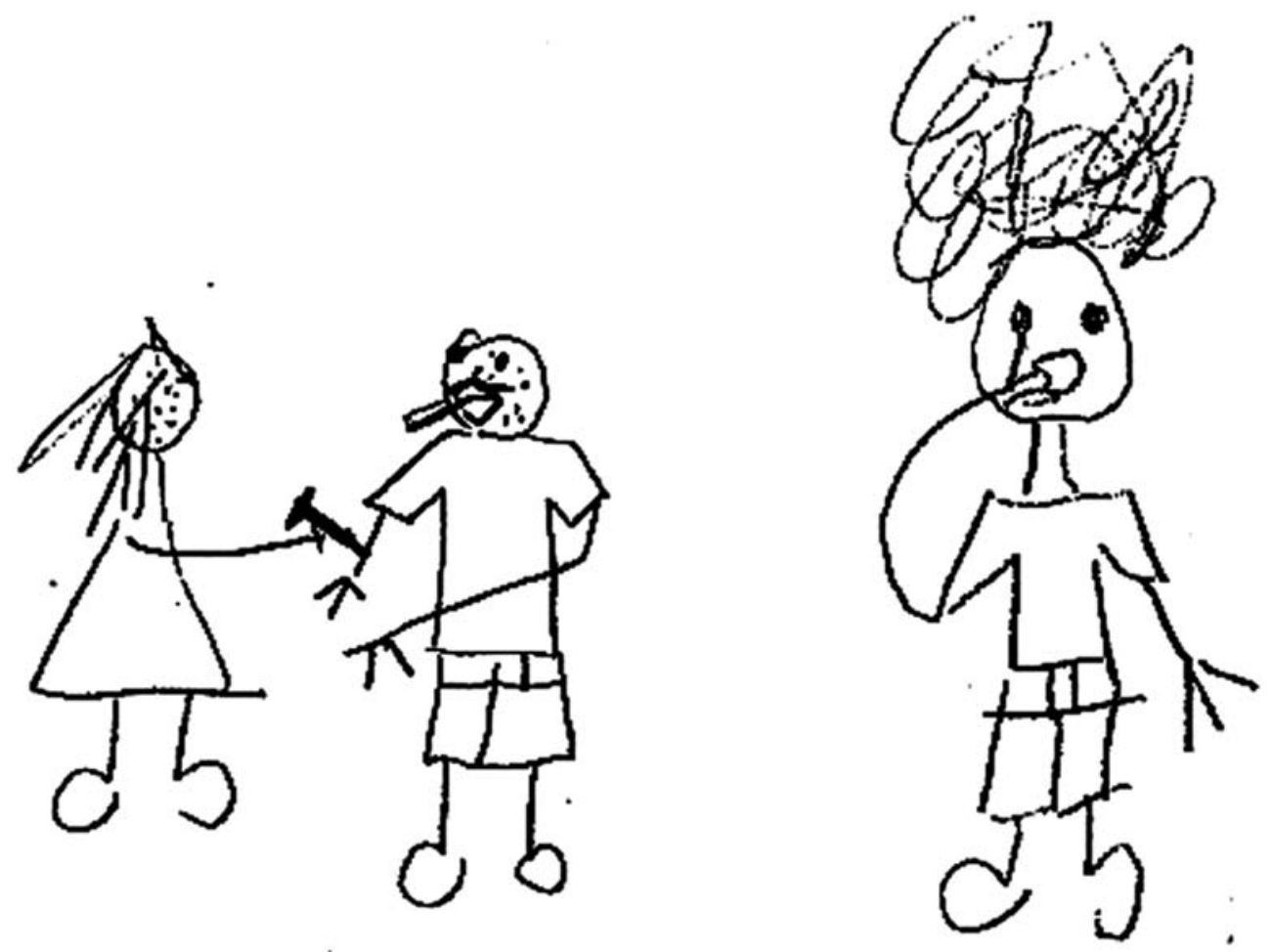

unhealthy eating (4 stories), receiving help from others (4 stories), transmission to others (3 stories), and losing hair ( 1 story). We present examples of these themes in stories below.

Stories in which a person with cancer undergoes surgery always resulted in positive health outcomes. Many stories assigned physical features to people before and after cancer. However, unlike the drawings of people with cancer, children described people with cancer in their stories as being bigger because of the presence of cancer in their bodies. A fifth-grade student wrote a story about a boy, Gabriel, whose grandmother was "chubby"/ "looked like a balloon" because she had cancer. After undergoing surgery, Gabriel's grandmother's physical features change because she was cured.

\section{[Untitled]}

There was a boy at school named Gabriel. His grandma was chubby. She started getting chubbier and chubbier. She looked like a balloon. One day they told her that the reason was that she had a cancer inside. They took her to a hospital and performed a surgery and they took out the cancer and then she no longer looked like a balloon nor looked chubby anymore and was cured.

Many stories discussed cancer as a consequence of smoking. Children described people who smoke as having a flawed character and were represented through villainous roles. In "The Chimney Man," one fifth grader narrated how there was a "bad man," Mr. Chimney, who smoked without regard to the consequences of his behavior. Eventually, Mr. Chimney realizes he has cancer and continues to smoke until he dies.

\section{"The Chimney Man"}

In the blue sky town there was a bad man that everyone called Mr. Chimney. They called him that because he was always smoking and looked like a chimney walking around town. The children yelled at him that he should not smoke because it was bad and he was going to die, but he didn't pay attention. One day he began to cough and cough and smoke came out of his nose and his ears when he coughed and it was that he had cancer. He continued smoking until he died. 
Table 1

Frequency of Stories' Thematic Content

\begin{tabular}{|c|c|c|}
\hline & Frequency & Percentage \\
\hline \multicolumn{3}{|l|}{$\begin{array}{l}\text { Stories about a person } \\
\text { with AIDS }(n=45)\end{array}$} \\
\hline Death & 24 & 54 \\
\hline Drug use & 15 & 33 \\
\hline Healing & 9 & 20 \\
\hline Pity & 7 & 16 \\
\hline Transmission to others & 6 & 13 \\
\hline Loneliness & 4 & 11 \\
\hline Sexual contact & 4 & 11 \\
\hline Begging for money & 3 & 7 \\
\hline Smoking & 3 & 7 \\
\hline $\begin{array}{l}\text { Transmission through } \\
\text { casual contact }\end{array}$ & 2 & 5 \\
\hline Being picked up by the police & 2 & 5 \\
\hline Condom use & 1 & 2 \\
\hline Being helped by other people & 1 & 2 \\
\hline Miraculous elements & 1 & 2 \\
\hline \multicolumn{3}{|l|}{$\begin{array}{l}\text { Stories about a person } \\
\quad \text { with cancer }(n=45)\end{array}$} \\
\hline Going through surgery & 21 & 47 \\
\hline Smoking & 15 & 33 \\
\hline Healing & 14 & 31 \\
\hline Death & 6 & 13 \\
\hline Unhealthy eating & 4 & 11 \\
\hline Being helped by other people & 4 & 11 \\
\hline Transmission to other people & 4 & 11 \\
\hline Losing hair & 1 & 2 \\
\hline \multicolumn{3}{|l|}{ Stories about a person with } \\
\hline \multicolumn{3}{|l|}{ AIDS and the child $(n=45)$} \\
\hline Transmission & 28 & 62 \\
\hline Initations to use drugs & 10 & 22 \\
\hline Getting the police & 2 & 5 \\
\hline Helping interactions & 4 & 11 \\
\hline Becoming friends & 3 & 7 \\
\hline
\end{tabular}

Note: There were 45 stories written on each category and some of them included more than one of the topics.

Although most students linked smoking with cancer, other students' narratives suggested children understood the role of genetics and other behaviors in cancer. In the following story, for example, a fifth grader narrated how a boy developed cancer just like his mother. Following his grandmother's advice, he adopts healthy habits, such as eating well and exercising. The fifth grader seems to believe that adopting these behaviors can cure developed cancer rather than help to prevent it.

[Untitled]

A boy got sick and he had cancer because his mom had cancer. His grandma told him that he should pray a lot and that if he ate well and exercised he was going to be cured. He saw that his mom died because she neither ate well nor exercised and decided to follow her grandma's advice and ate well and exercised and one day he started seeing his mom who was in heaven and he got cured.

\section{Stories About People With AIDS}

The most frequent themes in the stories about PWA with AIDS were death (24 stories) and drugs (15 stories). Some stories discussed themes including healing (9 stories), pity (7 stories), HIV transmission to others (6 stories), and loneliness (4 stories). Some included events where the characters were smoking (3 stories), transmitting HIV to others through casual contact (2 stories), getting picked up by the police (2 stories), using condoms (1 story), receiving help from others (1 story), and witnessing a miracle (1 story). Some of these themes intersect across the narratives. As with the drawings, many students described PWA through distinguishable physical features. One fifth-grade student, for example, described how Pepito, the main character in his story titled "My Last Day," develops AIDS through casual contact with a PWA "whose skin was covered with bubbles." In becoming a PWA, Pepito them becomes stigmatized and afraid of touching his loved ones for fear of infecting them.

\begin{abstract}
"My Last Day"
My name is Pepito and a man whose skin was covered with bubbles touched me and now I have AIDS. I am developing bubbles and people don't love me. I don't want to touch my mother so that she won't get the bubbles. Today is Thursday and I am very sick, I will die on Friday.
\end{abstract}

Many students voiced in their stories how PWA were not cared for by community members, who feared getting infected. These narratives illustrate how AIDS stigma curtails PWA's participation in supportive social networks. One child wrote a story in which the main character was an AIDS orphan who does not have anyone to take care of him. Although the boy with AIDS meets "a woman" who will care for him, she decides to not "want him" anymore because he has AIDS.

[Untitled]

The boy with AIDS was left abandoned. His mom and dad had AIDS and had died and now he has 
AIDS and nobody takes care of him or loves him. He is living alone like a homeless person without a house or anything. A woman was going to take care of him but when she found out that he had AIDS, she didn't want him anymore.

In other stories, children described PWA as being cared for by community members regardless of what other community members believed. In "The Girl from School," one fifth grader narrated how her main character, a beautiful girl who was "very, very skinny" and was suspected to have AIDS, was cared for by the fifth grader's mother. However, unlike others in the community, the PWA does not have a happy ending. In her conclusion, the fifth grader narrates how everyone was happy because "no one else got it." In most stories, developing AIDS lead to the physical deterioration and subsequent death of the character.

\section{"The Girl From School”}

This was a very beautiful girl but very, very skinny. Everybody said that she had AIDS and nobody took care of her. I told my mother and she took care of her. People used to tell her don't take care of her because you can get AIDS, but my mother picked her up and took her to the hospital and there they gave her food and she died and no one else got it and we all continued happy.

People with AIDS survive in only one narrative, "The Woman Who Prayed." In this story, the PWA, a woman who wishes to care for her children, gets cured through a miracle. This finding suggests fifth-grade children do not think it is possible to live with HIV/AIDS.

"The Woman Who Prayed"

A very sad woman had AIDS and was always praying to God asking him: "take the AIDS away from me so that I can take care of my children" and she prayed and prayed and one day she went to the doctor because she thought she was going to die and the doctor told her that God had paid attention to her and had cured her.

Many students narrated how developing AIDS was a consequence of a flawed character. In "Carlos," for example, a student narrates how the main character becomes sick because he is "dumb" and accepts "medicine" from a stranger in the park. Contrary to the drawings where syringes were detailed, most students who had drug use themes in their narratives did not clearly describe the connection between injection drug use and HIV/AIDS. However, children clarified these points during the debriefing.

\section{"Carlos"}

Carlos is a well behaved young man but very dumb. He went to school every day and came back home. One day he was at a park and a man gave him a medicine but it wasn't a medicine, it was drug and it had AIDS. Carlos got sick and stopped being a well behaved boy. He was unable to grow up and died.

\section{Stories About the Person With AIDS and the Child}

The themes found most frequently in the stories about the person with AIDS and the child were related to the PWA transmitting AIDS to the student (28 stories), whether by casual contact to the child (18 stories) or by offering drugs to the child (10 stories). Helping interactions (4 stories), becoming friends (3 stories), and calling the police (2 stories) were also mentioned in the stories where PWA and the children interact.

Similar to the drawings about PWA, children frequently narrated how AIDS was developed through casual contact with a PWA, leading to their infection and the infection of their loved ones. One fifth grader, for example, narrated about how a child with AIDS who played in the park began an epidemic that killed the entire town.

\section{[Untitled]}

One day at the park there was a boy who had AIDS and the children didn't know it and he was always with blood and with drugs. He began to touch all of us children at school and everyone got sick and they touched their fathers and mothers at their houses, they got sick too. When their parents touched their siblings they also got sick. Everybody in the town died and it was all the fault of the kid who used drugs and was with blood.

Few children discussed sexual behavior in their narratives. Most often, PWA described in these stories engaged in sexual behaviors and used drugs. In one narrative, for example, a fifth grader described how she knew a boy named Xavier who was very attractive and who had acquired AIDS because he had many girlfriends and used drugs. Contrary to previous 
descriptions of PWA, Xavier's attractiveness is highlighted to justify why he had so many girlfriends (e.g., "he is very cute"). However, the student narrates how she stopped being his friend because he offered her drugs.

\section{[Untitled]}

A boy called Xavier became my friend and he was very cute. He had AIDS because he had many girlfriends and used drugs and I didn't know it. One day he offered me drugs and I said no and he wasn't my friend anymore. He continues going out with many girls and giving them drugs because he is very cute.

\section{Discussion}

Overall, our findings suggest that Puerto Rican children have strong stigma, both instrumental and symbolic, toward people with AIDS. Instrumental stigma toward PWA (e.g., fears stemming from worries about contagion) are evident across numerous references to transmission and fear of people with AIDS. Children held highly stereotypical images of people with AIDS, typically attributing malevolent intent to them and associating them with deteriorated bodies. Building on Ramirez and Vargas's (1996) study, we found that children highlighted different characteristics in their representations of PWA, depending on the data collection technique used. In their drawings, Puerto Rican children represented instrumental stigma by portraying PWA as physically deteriorated (i.e., sores, decaying teeth, skinny) and being scared of contagion when drawn next to a PWA. In their stories, we found similar results to those of Ramirez and Vargas's (1996) study. Children highlighted their fear of being infected with HIV/AIDS through casual contact with a PWA and the imminence of death if you developed AIDS. Furthermore, contrary to the drawings, children's stories usually highlighted the PWA's individual responsibility for getting infected (e.g., disobeying parents, not following advice). Taken together, the drawings and stories about PWA suggest that Puerto Rican fifthgrade students might be uninformed about how HIV is transmitted and might believe that people living with AIDS are identifiable through their physical appearance or select behaviors.

We also found evidence of symbolic stigma (e.g., negative representations of PWA as members of a socially marginalized group). PWA were most often represented as carrying syringes in youth's drawings and stories. The representation of injection drug-using PWA in children's drawings and stories, however, highlighted different attributes. In their drawings, children portrayed PWA as malevolent by drawing characters that, aside from carrying a syringe, possessed a weapon (e.g., knife or gun). Although this theme was also evident in children's stories, PWA were also portrayed as trying to harm the child by offering drugs or by trying to harm them physically with a weapon. The association between drug use and PWA in children's representations might highlight their awareness of efforts to decrease HIV transmission through mass media campaigns, given the high proportion of AIDS cases due to injection drug use in Puerto Rico. Nonetheless, an unintended consequence of these public health efforts might be the further criminalization and stigmatization of injection drug users.

There were no linkages between AIDS and sexual behavior in the drawings of PWA. In the stories, only two references to sexual behaviors were made, and they referred to "having many girlfriends." These findings suggest that there is either lack of information about a relationship about AIDS risks and sex behaviors, or that children chose to avoid discussing sex in their drawings and stories about sex because of taboos. The AIDS education session after each data collection suggest that the first explanation is more likely. Recently, sex education has been instituted for children ages 6 to 12 in public schools. We believe this effort is aimed in the right direction, particularly as most of the children in our study had no knowledge about sexual behavior and how it related to HIV infection. Students were often unable to distinguish between casual contact and sexual contact. Many children, for example, asked questions about why casual contact (i.e., kissing or hugging) did not lead to HIV infection, even though other people in their lives, usually their parents, had told them that you could get AIDS from sex. Three students disclosed that they knew about sex risk behaviors and discussed condom use privately with the researchers. As appropriately pointed out by one of the anonymous reviewers, however, it is possible that students might have felt reluctant to talk about sexual modes of transmission at school. Although we found no differences between religious and nonreligious schools, future research should explore whether preadolescent youth feel more comfortable discussing these issues in their stories and drawings if the data are collected in nonschool settings. 
Preadolescent youth's stigma toward PWA seems to be distinctive from other representation of illness. Compared to their portrayals of people who were healthy, who had a cold, or who had cancer, children portrayed PWA disapprovingly. Although some children portrayed people with cancer negatively in their stories and drawings, PWA were most often portrayed as a danger to society and a risk to the community's well-being. The differences in children's representations of PWA when compared to the other three sick-role scenarios might relate to the gravity of the disease. Whereas getting a cold and, to some extent, having cancer have medical remedies, the absence of a cure for HIV/AIDS might increase children's perceived severity of the disease. At this time, however, we are unable to conclude whether Puerto Rican children's perceived severity is intricately related to differences in disease-specific stigma. Although we had a large sample size, our exploratory analyses were not focused on developing a formal theory through thematic saturation. Future research should explore using a grounded theory approach whether preadolescent children hold other attitudes and beliefs regarding AIDS stigma (Walker \& Myrick, 2006).

Our study has several additional limitations. First, our findings are limited to preadolescent Puerto Rican children in the fifth grade. Similar to research with other populations (Kistner et al., 1997), future research should explore whether there are differences in children's AIDS-related attitudes across different grade levels. Second, participants might have exaggerated the use of physical marks of illness in the drawings to differentiate the person with AIDS from the people with other sick-role scenarios. Future studies should be performed to replicate our findings. Furthermore, we recommend the inclusion of colored pencils to explore whether students portray additional diseaserelated elements through colors in their drawings (Guillemin, 2004). Third, it is possible that some fifth graders felt less comfortable in their drawing abilities than other peers. Although we have no evidence to suggest that this occurred, future research should explore whether there are grade-level or age differences in students' comfort in using drawings as a data collection procedure. Fourth, time constraints in the classroom limited our ability to explore how Puerto Rican children create stories about people who are healthy or who have a cold. Given the differences portrayed in children's drawings, future research should explore how children portray these two situations. Finally, the findings can not be generalized to all 10-year-old children in Puerto Rico. Children attending public schools might have different attitudes toward PWA than their private school counterparts. Future research should assess whether these differences exist by school type.

These limitations notwithstanding, our findings suggest that the children in our sample had negative perceptions and opinions about PWA and would be unlikely to interact with PWA in a positive manner. Future studies should look at how these attitudes interferes with AIDS education as children transition into adolescence and begin to explore their sexuality. Although current theoretical frameworks like the Theory of Reasoned Action (Montaño \& Kasprzyk, 2002) and Social Cognitive Theory (Bandura, 2004) assert that individuals' attitudes play a part in the likelihood of engaging in safer sex practices across the life course, instrumental and symbolic stigma toward PWA have received little attention as potentially salient attitudes influencing sexually maturing youth's sexual decision making. Our findings suggest that sex education programs targeting preadolescent youth should include activities to reduce instrumental and symbolic AIDS stigma, respectively. We hope this study is a stepping-stone for additional theoretical expansion regarding how stigma influences youth's sexual decision making.

Our study highlights the importance of assessing children's attitudes through creative data collection approaches. We believe it necessary to continue exploring the knowledge, attitudes and behaviors of children, adolescents, and adults in the Puerto Rican population to develop, implement, and disseminate effective prevention programs. Future studies should explore whether these qualitative approaches provide similar information to traditional questionnaires assessing children's attitudes toward PWA, or whether they should be used as adjunct data collection techniques.

\section{References}

Aldridge, J., Lamb, M. K., Sternberg, K. J., Orbach, Y., Esplen, P. W., \& Bowler, L. (2004). Using a human figure drawing to elicit information from alleged victims of child sexual abuse. Journal of Consulting and Clinical Psychology, 72(2), 304-316.

Allan Guttmacher Institute. (2005). Sex education: Needs, programs, and policies. Retrieved August 16, 2005, from http:// www.agi-usa.org/presentations/ed_slides.html

Bandura, A. (2004). Health promotion by social cognitive means. Health Education \& Behavior, 31(2), 143-164. 
Bendelow, G., \& Pridmore, P. (1998). Children's images of health. In A. Petersen \& C. Waddell (Eds.), Health matters: A sociology of illness, prevention, and care (pp. 128-140). Sydney: Allen and Unwin.

Burkitt, E., Barrett, M., \& Davis, A. (2005). Drawings of emotionally characterized figures by children from different educational backgrounds. International Journal of Art and Design Education, 24(1), 71-83.

Capitanio, J. P., \& Herek, G. M. (1999). AIDS stigma and attitudes toward injecting drug users among Black and White Americans. American Behavioral Scientist, 42, 1148-1161.

Centers for Disease Control and Prevention. (2005). 2004 AIDS surveillance report. Atlanta, GA: Author.

Cole, K. L., Roberts, M. C., \& McNeal, R. E. (1996). Children's perceptions of ill peers: Effects of disease, grade, and impact variables. Children's Health Care, 25(2), 107-115.

Cox, S. (2005). Intention and meaning in young children's drawings. International Journal of Art and Design Education, 24(2), 115-125.

Diem-Wille, G. (2001). A therapeutic perspective: The use of drawings in child psychoanalysis and social science. In T. V. Leeuwen \& C. Jewitt (Eds.), Handbook of visual analysis (pp. 119-133). Thousand Oaks, CA: Sage.

Fury, G., Carlson, E., \& Sroufe, A. (1997). Children's representations of attachment relationships in family drawings. Child Development, 68(6), 1154-1164.

Goffman, E. (1963). Stigma: Notes on the management of spoiled identity. Englewood Cliffs, NJ: Prentice Hall.

González, M. (1997, July). Me evitan porque tengo SIDA, me duele, no me importa: Mujeres experimentando estigma [They avoid me because I have AIDS, it hurts, but it doesn't matter: Women experiencing stigma]. Paper presented at the TwentySixth Interamerican Psychology Congress, Sao Paulo, Brazil.

Guillemin, M. (2004). Understanding illness: Using drawings as research method. Qualitative Health Research, 14, 261-280.

Hamra, M., Ross, M. W., Karuri, K., Orrs, M., \& D’Agostino, A. (2005). The relationship between expressed HIV/AIDS stigma and beliefs and knowledge about care and support of people living with AIDS in families caring for HIV-infected children in Kenya. AIDS Care, 17(7), 911-922.

Henker, B., Whalen, C. K., \& O'Neil, R. (1995). Worldly and workaday worries: Contemporary concerns of children and young adolescents. Journal of Abnormal Child Psychology, 23, 685-702.

Herdt, G. (2001). Stigma and the ethnographic study of HIV: Problems and prospects. AIDS and Behavior, 5(2), 141-149.

Herek, G. M. (1999). AIDS and stigma. American Behavioral Scientist, 42, 1106-1116.

Herek, G. M., \& Capitanio, J. P. (1999). AIDS stigma and sexual prejudice. American Behavioral Scientist, 42, 1130-1147.

Herek, G. M., Capitanio, J. P., \& Widaman, K. F. (2002). HIVrelated stigma and knowledge in the United States: Prevalence and trends, 1991-1999. American Journal of Public Health, 92(3), 371-377.

Herek, G. M., Capitanio, J. P., \& Widaman, K. F. (2005). Stigma, social risk, and health policy: Public attitudes toward HIV surveillance policies and the social construction of illness. Health Psychology, 22(5), 533-540.

Hoppe, M., Wells, E. A., Wilsdon, A., Gillmore, M. R., \& Morrison, D. M. (1994). Children's knowledge and beliefs about AIDS: Qualitative data from focus group interviews. Health Education Quarterly, 21, 117-126.

Irwin, L. G., \& Johnson, J. (2005). Interviewing young children: Explication our practices and dilemmas. Qualitative Health Research, 15, 821-831.

Kendrick, M., \& McKay, R. (2002). Uncovering literacy narratives through children's drawings. Canadian Journal of Education, 27(1), 45-61.

Kistner, J., Eberstein, I. W., Quadagno, D., Sly, D., Sittig, L., Foster, K., et al. (1997). Children's AIDS-related knowledge and attitudes: Variations by grade, race, gender, socioeconomic status, and size of community. AIDS Education and Prevention, 9(3), 285-298.

Montaño, D. E., \& Kasprzyk, D. (2002). The theory of reasoned action and the theory of planned behavior. In K. Glanz, B. K. Rimer, \& F. M. Lewis (Eds.), Health behavior and health education: Theory, research, and practice (pp. 67-98). San Francisco: Jossey-Bass.

Parker, R., \& Aggleton, P. (2003). HIV and AIDS stigma and discrimination: A conceptual framework and implications for action. Social Science and Medicine, 57(1), 13.

Pryor, J. B., Reeder, G. D., \& Landau, S. (1999). A socialpsychological analysis of HIV-related stigma: A two-factor theory. American Behavioral Scientist, 42, 1193-1211.

Pryor, J. B., Reeder, G. D., Yeadon, C., \& Hesson-McInnis, M. (2004). A dual-process model of reactions to perceived stigma. Journal of Personality and Social Psychology, 87(4), 436.

Ramirez, M., \& Vargas, M. (1996). La percepción de un grupo de niños y niñas de Segundo grado sobre el SIDA [The perception of a group of second graders about AIDS]. Unpublished manuscript, Center for Research and Education on HIV/AIDS, University of Puerto Rico, Rio Piedras.

Ramirez-Valles, J., Fergus, S., Reisen, C. A., Poppen, P. J., \& Zea, M. C. (2005). Confronting stigma: Community involvement and psychological well-being among HIV-positive Latino gay men. Hispanic Journal of Behavioral Sciences, 27(1), 101-119.

Reidpath, D. D., \& Chan, K. Y. (2005). A method for the quantitative layering of HIV-related stigma. AIDS Care, 17(4), 425-432.

Schiff, M., McKay, M., Bell, C., Baptiste, D., Madison, S., \& Paikoff, R. (2003). The role of personal contact with HIVinfected people in explaining urban, African American preadolescents' attitudes toward peers with HIV/AIDS. American Journal of Orthopsychiatry, 73(1), 101-108.

Siegel, L. (1993). Children's understanding of AIDS: Implications for preventive interventions. Journal of Pediatric Psychology, 18, 173-176.

Sumida, A. Y. (2000). Reading a child's writing as a social text. Language Arts, 77(4), 309-315.

Tinsley, B. J., Lees, N. B., \& Sumartojo, E. (2004). Child and adolescent HIV risk: Familial and cultural perspectives. Journal of Family Psychology, 18(1), 208-224.

United States Census. (2006). Puerto Rico by county. Retrieved November 9, 2006, from http://factfinder.census.gov

Varas-Diaz, N., Serrano-Garcia, I., \& Toro-Alfonso, J. (2005). AIDS stigma and social interaction: Puerto Ricans living with HIV/AIDS. Qualitative Health Research, 15, 169-187.

Walker, D., \& Myrick, F. (2006). Grounded theory: An exploration of process and procedure. Qualitative Health Research, $16,547-559$. 
Wang, C. C. (1998). Portraying stigmatized conditions: Disabling images in public health. Journal of Health Communication, 3 , 149-159.

Yuen, F. C. (2004). "It was fun . . I liked drawing my thoughts": Using drawings as a part of the focus group process with children. Journal of Leisure Research, 36(4), 461-483.
Milagritos González-Rivera, $\mathrm{PhD}$, is a professor in the Social Sciences Department at the University of Puerto Rico, Mayagüez.

José A. Bauermeister, MPH, is a doctoral candidate in the Department of Health Behavior and Health Education at the School of Public Health, University of Michigan, Ann Arbor. 